\title{
Increased saliva oestriol to progesterone ratio before idiopathic preterm delivery: a possible predictor for preterm labour?
}

\author{
J DARNE, H H G MCGARRIGLE, GILLIAN C L LACHELIN
}

\begin{abstract}
Saliva oestriol, oestradiol, and progesterone concentrations were measured in 23 women who went into spontaneous preterm labour. The patients fell clinically and biochemically into two groups. The 13 who went into preterm labour with intact membranes had a saliva oestriol to progesterone ratio greater than one in every case and greater than the 95th centile for their length of gestation in 12 cases; by contrast, all those who went into spontaneous preterm labour after prolonged rupture of the membranes had an oestriol to progesterone ratio less than one and below the 50th centile for their period of gestation in the one to four days before delivery. Saliva oestradiol to progesterone ratios were randomly distributed throughout the normal range in both groups.
\end{abstract}

It appears that preterm labour without prior prolonged rupture of the membranes is, like term labour, preceded by an increase in the saliva oestriol to progesterone ratio. It may therefore be possible to use this ratio to predict preterm labour.

\section{Introduction}

Preterm delivery is a main cause of neonatal morbidity and mortality in Britain. The mechanisms underlying the onset of idiopathic preterm labour are poorly understood, and if the incidence of preterm labour is to be reduced we must increase our understanding of the events that lead up to it. saliva oestriol, oestradiol, and progesterone concentrations 23 women who went into spontaneous preterm labour.

\section{Patients and methods}

Patients at risk for preterm labour were recruited either on the basis of their past obstetric history or after admission to hospital with threatened preterm labour. They fell into two clinical groups. One group (13 patients) had intact membranes and increased uterine activity and the other groum (10 patients) had prolonged preterm rupture of the membranes. All wew into labour spontaneously and delivered before 37 weeks of gestation. The patients were compared with 20 normal women who went into spontaneovis labour at term (see table)

Three of the 13 women in the first group had had intermittent vaginis bleeding during the four weeks before the onset of labour. Seven women i this group received treatment with $\beta$ sympathomimetics for varying periods The 10 women with spontaneous preterm rupture of the membranes werd treated conservatively, and all eventually went into labour spontaneous before 37 weeks (mean duration of ruptured membranes 25 days, range three to 70). None of the patients were given corticosteroids or antibiotics.

Saliva specimens were collected once a day at about the same time and stored at $-40^{\circ} \mathrm{C}$ until assayed. All samples from a particular patient were assayed in duplicate in the same assay for oestriol, progesterone, arof oestradiol by radioimmunoassay, as described. ${ }^{7}$ Briefly, for measurements oestriol and progesterone duplicate $250 \mu \mathrm{l}$ saliva samples were mixed witt $125 \mu \mathrm{l}$ of $1.5 \mathrm{M}$ sodium carbonate buffer $\mathrm{pH} 10.5$ and extracted with $3 \mathrm{mo}$ freshly distilled diethyl ether. The ether was evaporated and the residue dissolved in $500 \mu \mathrm{l}$ phosphate buffered saline. Separate $200 \mu \mathrm{l}$ aliquots we taken and the oestriol and progesterone content measured by radioimmune

Clinical details of patients going into spontaneous labour. Figures are median values (ranges in parentheses)

\begin{tabular}{lcccc}
\hline & $\begin{array}{c}\text { No of } \\
\text { patients }\end{array}$ & $\begin{array}{c}\text { Age } \\
\text { (years) }\end{array}$ & $\begin{array}{c}\text { Gestation at delivery } \\
\text { (weeks) }\end{array}$ & $\begin{array}{c}\text { Birth weight } \\
\text { (g) }\end{array}$ \\
\hline Preterm labour with intact membranes & 13 & $29(22-37)$ & $29(23-34)$ & $1525(555-1915)$ \\
Preterm labour with prolonged rupture of membranes & 10 & $27(23-37)$ & $32 \cdot 5(27-35)$ & $1832(994-2420)$ \\
Term labour & 20 & $31 \cdot 5(28-38)$ & $40(38-41)$ & $3190(2960-3760)$ \\
\hline
\end{tabular}

Most endocrine studies have been directed towards investigating changes in plasma oestradiol and progesterone concentrations before preterm labour. ${ }^{1.3}$ Measurements of these hormones have not been found to be useful in predicting preterm labour. ${ }^{45}$

We have recently reported finding a consistent rise in the saliva oestriol to progesterone ratio some days before the spontaneous onset of labour at term. ${ }^{67}$ Saliva oestrogen and progesterone concentrations reflect the unbound, unconjugated (free, biologically active) plasma steroid concentrations, and saliva estimations have the added advantage that samples can be collected frequently with minimal inconvenience to patients. We have therefore measured

Obstetric Unit, University College and Middlesex School of Medicine, London WC1E 6HX

J DARNE, MRCOG, research registrar

H H G MCGARRIGLE, PHD, principal biochemist

GILLIAN C L LACHELIN, MD, FRCOG, reader

Correspondence to: Miss Lachelin. assay using tritium labelled oestriol and progesterone. For oestradio measurement duplicate $500 \mu \mathrm{l}$ saliva samples were mixed with $250 \mathrm{~W}$ sodium carbonate buffer and extracted with $5 \mathrm{ml}$ diethyl ether; after evaporation of the ether the residue was chromatographed on Sephades LH20 columns using a benzene and methanol (85:15) mixture. The eluare fraction containing oestradiol was collected and evaporated and the oestradiol content measured by radioimmunoassay using tritium labell\&g oestradiol.

\section{Results}

We had previously measured saliva oestriol, progesterone, and oestradio concentrations twice a week from 18 weeks of gestation and daily for tre last 38 days before delivery in 20 normal women with uncomplicatef pregnancies who went into spontaneous labour at term and were delivered $\odot$ f a healthy baby of normal birth weight. ${ }^{7}$ The oestriol to progesterone and oestradiol to progesterone ratios were calculated for all the specimens 20 and 15 of these subjects, respectively, and the medians and 5th, 90th, and 95 th centiles computed. The results from that study were used as the normal range of values for comparison with the women going into preterm labour the current study. As the number of specimens collected from the patients 
going into preterm labour varied from one patient to another (range two to 68 ) we plotted the mean ratios in the daily samples obtained in the last one to four days before delivery (see figs 1 and 2).

As far as the oestriol to progesterone ratio was concerned the patients fell both clinically and biochemically into two groups (fig 1). In all 13 women

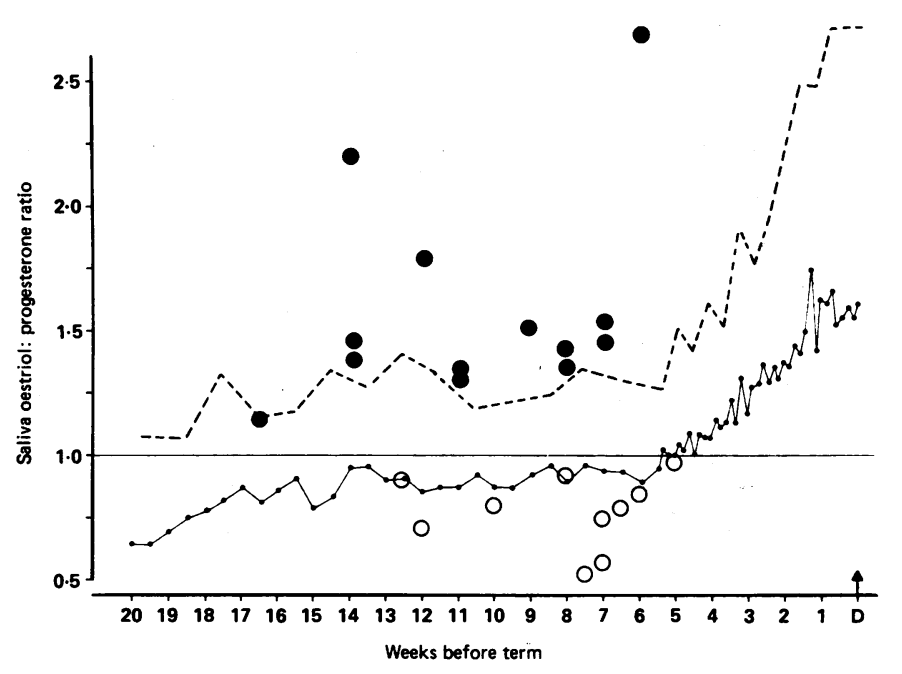

FIG 1-Median (solid line) saliva oestriol to progesterone ratios in 20 normal women till day of term delivery (D). Dotted line represents 95 th centile. ${ }^{7}$ Solid circles represent mean oestriol to progesterone ratio in last one to four days before delivery in 13 women going into idiopathic preterm labour with intact membranes. Open circles represent mean ratio in last one to four days before delivery in 10 women going into spontaneous labour after prolonged preterm rupture of membranes. Circles placed at number of weeks before 40 weeks' gestation that delivery occurred.

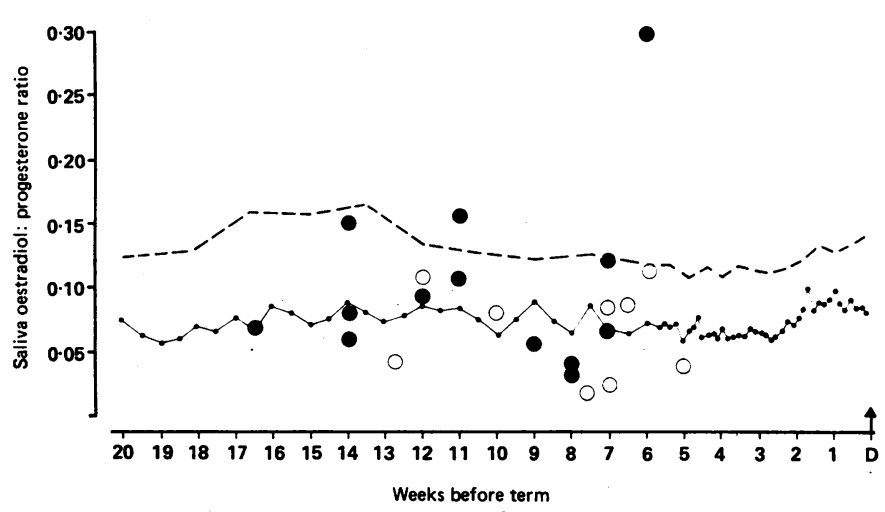

FIG 2-Median (solid line) saliva oestradiol to progesterone ratios in 15 norma women till day of term delivery (D). Dotted line represents 95 th centile. ${ }^{7}$ Solid circles represent mean oestradiol to progesterone ratio in last one to four days before delivery in 13 women going into idiopathic preterm labour with intact membranes. Open circles represent mean ratio in last one to four days before delivery in nine women going into spontaneous labour after prolonged preterm rupture of membranes. (There was insufficient saliva to measure oestradiol concentrations in 10th patient.) Circles placed at number of weeks before 40 weeks' gestation that delivery occurred.

who went into preterm labour with intact membranes the oestriol to progesterone ratio was abnormally high for the period of gestation-that is, greater than the 95 th centile in 12 patients and greater than the 90 th centile in all cases. By contrast, the oestriol to progesterone ratios in the 10 women with prolonged preterm rupture of the membranes were consistently in the lower part of the normal range for the length of gestation, and these ratios did not change before the spontaneous onset of labour and remained at less than one in every case.

The increase in the oestriol to progesterone ratio in the group with intact membranes was due to a raised oestriol concentration rather than a low progesterone value. All the oestriol concentrations in this group were above the 50th centile for gestation, and in five cases the concentration was above the 95th centile; most of the progesterone concentrations in this group were also above the 50 th centile for gestation but were raised less than the oestriol concentrations in every case.

In the 10 patients with prolonged rupture of the membranes the oestriol and progesterone concentrations were between the 5 th and 95 th centiles for gestation in all cases and the oestriol to progesterone ratio was less than one in every case.

Oestradiol concentrations and oestradiol to progesterone ratios were randomly distributed throughout the normal range in both groups (fig 2).

\section{Discussion}

We have previously shown that the spontaneous onset of labour at term is preceded by a definite increase in the saliva oestriol to progesterone ratio. Saliva steroid concentrations reflect the unbound, unconjugated (free, biologically active) plasma steroid concentrations. That a rise in free oestrogen should precede the onset of labour accords with the known effects of oestrogen and progesterone on myometrial activity. ${ }^{67}$ Other studies have focused on measurements of oestradiol, as oestriol had been thought to be a weak oestrogen; but now it is apparent that oestriol may be as active as oestradiol in specific target tissues. For instance, oestriol binds to myometrial oestrogen receptors ${ }^{8}$ and is as effective as oestradiol in stimulating production of prostaglandin $F_{2 \alpha}$ by human endometrial cells in culture. ${ }^{9}$ Furthermore, free oestriol concentrations are 10 to 20 times greater than free oestradiol concentrations in late pregnancy. ${ }^{67}$

We found only a minimal increase in the saliva oestradiol to progesterone ratio before the onset of labour at term in our previous study $^{7}$ (fig 2) and did not find any increase in the saliva oestradiol to progesterone ratio in women going into preterm labour in this study. Earlier studies similarly failed to show an increase in the plasma oestradiol to progesterone ratio before preterm labour. ${ }^{45}$

From this study it appears that a rise in the oestriol to progesterone ratio may precede the onset of idiopathic preterm labour and that the normal endocrine changes that precede term labour occur inappropriately early. The normal rise in oestriol in late pregnancy may be due to increased fetal adrenal activity. There is some evidence to support the idea that increased fetal adrenal activity occurs before the onset of preterm labour. Corrected mean adrenal weights in 64 preterm babies who were either stillborn or died within 12 hours of birth were roughly $25 \%$ greater in those delivered after idiopathic preterm labour than in those whose delivery occurred after sudden antepartum haemorrhage..$^{10}$ It is noteworthy that in five of our 13 cases of preterm labour with intact membranes the saliva oestriol concentrations were above the 95 th centile and that they were above the 50th centile in all cases, suggesting increased fetal adrenal activity in this group.

There is an increase in uterine gap junction formation and in the number of myometrial oxytocin receptors in women in preterm labour as well as those in labour at term, ${ }^{11}{ }^{12}$ and peripheral concentrations of prostaglandin metabolites are raised in both term and preterm labour. ${ }^{13}$ It is known that oestrogen enhances and progesterone suppresses these developments. An increase in spontaneous uterine activity and in uterine sensitivity to oxytocin have also been found in some women subsequently going into idiopathic preterm labour. ${ }^{14} 15$

The underlying cause of preterm labour after prolonged preterm rupture of the membranes is clearly different from that of preterm labour with intact membranes. Possibly local infection may weaken the membranes and lead to their spontaneous rupture. ${ }^{16}{ }^{17}$ Several organisms have been found to possess greater phospholipase $A_{2}$ activity than that of the membranes and it has been suggested that this may cause increased prostaglandin production by the membranes. ${ }^{1819}$ Thus bacterial infection might lead to the onset of labour by a method which bypasses the increase in the oestrogen to progesterone ratio that normally occurs before labour.

Clinical scoring systems ${ }^{2021}$ and biochemical ${ }^{22}$ and biophysical ${ }^{23}$ markers that have been tried for predicting preterm labour have not been very helpful in practice. From our study it appears that preterm labour without prior prolonged rupture of the membranes is preceded by an increase in the saliva oestriol to progesterone ratio. 
If this occurs as long before the onset of preterm labour as does the increase in the saliva oestriol to progesterone ratio before the spontaneous onset of labour at term it might be possible to use measurements of this ratio to predict preterm labour-and so initiate treatment in time to prevent its occurrence in some cases. Studies are currently underway to address this issue.

We are very grateful to the University College Appeal Trust for the support of JD and to Clare Thomson for excellent secretarial work.

\footnotetext{
References

1 Tamby Raja RL, Anderson ABM, Turnbull AC. Endocrine changes in premature labour. BrMed f 1974; ;iv:67-71.

2 Cousins LM, Hobel CJ, Chang RJ, Okada DM, Marshall JR. Serum progesterone and estradiol$17 \beta$ levels in premature and term labor. Am $\mathcal{O}$ Obstet Gynecol 1977;127:612-5.

3 Csapo AL. The "seesaw" theory of parturition. In: Knight J, O'Connor M, eds. The fetus and birth. Amsterdam: Elsevier North Holland, 1977:159-210.

4 Bell R. Antenatal oestradiol and progesterone concentrations in patients subsequently having preterm labour. Br $\mathcal{X}$ Obstet Gynaecol 1983;90:888-91.

5 Block BSB, Liggins GC, Creasy RK, Preterm delivery is not predicted by serial estradiol or progesterone concentration measurements. Am J Obstet Gynecol 1984;150:716-22.

6 McGarrigle HHG, Lachelin GCL. Increasing saliva (free) oestriol to progesterone ratio in late pregnancy: a role for oestriol in initiating spontaneous labour in man? $\mathrm{Br} M$ Med $\mathcal{f} 1984 ; 289: 457-9$.

7 Darne J, McGarrigle HHG, Lachelin GCL. Saliva oestriol, oestradiol, oestrone and progesterone levels in pregnancy: spontaneous labour at term is preceded by a rise in the saliva oestriol progesterone ratio. Br $\mathcal{F}$ Obstet Gynaecol (in press).

8 Wiegerinck MAHM, Poortman J, Donker TH, Thijssen JHH. In vivo uptake and subcellular
}

distribution of tritium-labeled estrogens in human endometrium, myometrium, and vagirm f Clin Endocrinol Metab 1983;56:76-86. 9 Schatz F, Markiewicz L, Gurpide E. Effects of estriol on PGF2 ${ }_{a}$ output by cultures of human endometrium and endometrial cells. J Steroid Biochem 1984;20:999-1003.

10 Anderson ABM, Laurence KM, Davies K, Campbell H, Turnbull AC. Fetal adrenal weight afit the cause of premature delivery in human pregnancy. Fourmal of Obstetrics and Gynaecology of the British Commonwealth 1971;78:481-8.

11 Garfield RE, Hayashi RH. Appearance of gap junctions in the myometrium of women during labor. Am $\mathcal{O}$ Obstet Gynecol 1981;140:254-60.

12 Fuchs A-R, Fuchs F, Husslein P, Soloff MS. Oxytocin receptors in the human uterus durif pregnancy and parturition. Am $\mathcal{f}$ Obstet Gynecol 1984;150:734-41.

13 Sellers SM, Mitchell MD, Bibby JG, Anderson ABM, Turnbull AC. A comparison of plasm prostaglandin levels in term and preterm labour. Br $\mathcal{Y}$ Obstet Gynaecol 1981;88:362-6.

$14 \mathrm{Katz}$ M, Newman RB, Gill PJ. Assessment of uterine activity in ambulatory patients at high risk preterm labor and delivery. Am f Obstet Gynecol 1986;154:44-7.

15 Takahashi K, Diamond F, Bieniarz J, Yen H, Burd L. Uterine contractility and oxytoci sensitivity in preterm, term, and postterm pregnancy. Am $\mathcal{F}$ Obstet Gynecol 1980;136:774-9.

16 Naeye RL, Peters EC. Causes and consequences of premature rupture of fetal membranes. Lancet 1980;i:192-4.

17 Regan JA, Chao S, James LS. Premature rupture of membranes, preterm delivery, and group streptococcal colonization of mothers. Am $\mathcal{J}$ Obstet Gynecol 1981;141:184-6.

18 Bejar R, Curbelo V, Davis C, Gluck L. Premature labor. II. Bacterial sources of phospholipase Obstet Gynecol 1981;57:479-82.

19 Lamont RF, Rose M, Elder MG. Effect of bacterial products on prostaglandin E production by amnion cells. Lancet 1985;ii:1331-3.

20 Fedrick J. Antenatal identification of women at high risk of spontaneous pre-term birth. $\mathrm{Br}-7$ Obstet Gynaecol 1976;83:351-4.

21 Creasy RK, Gummer BA, Liggins GC. System for predicting spontaneous preterm birth. Obs Gynecol 1980;55:692-5.

22 Westergaard JG, Teisner B, Hau J, Grudzinskas JG. Placental protein measurements 올 complicated pregnancies. III. Premature labour. Br J Obstet Gynaecol 1984;91:1230-3.

23 Castle BM, Turnbull AC. The presence or absence of fetal breathing movements predicts outcome of preterm labour. Lancet 1983;ii:471-2.

(Accepted 12 November 1986)

\title{
Impact of gestrinone on the course of asymptomatic endometriosis
}

\author{
ERIC J THOMAS, IAN D COOKE
}

\begin{abstract}
A new drug, gestrinone, was subjected to the first double blind, randomised placebo controlled trial of any treatment of endometriosis. The disease deteriorated in eight $(47 \%)$ of the 17 patients prescribed placebo (95\% confidence limits $23 \%$ and $71 \%$ ) compared with none of the 18 patients prescribed gestrinone $(p=0.002)$. There was a difference in elimination of the endometriosis in the gestrinone group compared with placebo but this was not statistically significant $(p=0.057)$. There was a significant difference in improvement of the disease in the gestrinone group compared with placebo $(p=0.004)$, confirming that gestrinone is an effective treatment of endometriosis.

Endometriosis deteriorates in at least $23 \%$ of patients; as it is impossible to predict in whom this will happen, treatment appears to be warranted in all cases.
\end{abstract}

\section{Introduction}

Androgens, ${ }^{1}$ progestogens, ${ }^{2}$ danazol, ${ }^{36}$ and luteinising hormone releasing hormone agonists ${ }^{78}$ have all been shown to improve endometriosis either clinically or visually in uncontrolled trials.

\footnotetext{
University Department of Obstetrics and Gynaecology, The Jessop Hospital for Women, Sheffield

ERIC J THOMAS, MRCOG, lecturer

IAN D COOKE, FRCOG, professor

Correspondence to: Dr Thomas.
}

Before the advent of laparoscopy only symptomatic disease wâ treated, but now it is becoming increasingly common to diagno asymptomatic disease, especially in infertile women. The relevance of the finding is unknown and it may be solely a reflection of a increased prevalence of the disease in nulliparous patients, who ate overrepresented in infertile women. ${ }^{9}$ The problem is compounder by the fact that there is no placebo controlled trial of any treatmen of endometriosis and therefore no information about the cours of the disease. Possibly asymptomatic endometriosis resolves spontaneously in most women. These uncertainties have resulted $\mathbf{m}$ some clinicians treating and others not treating asymptomatic endometriosis. The introduction of gestrinone (Roussel-UCLAF Paris) for phase III clinical trials provided a unique opportunity to perform a placebo controlled trial of a treatment of endometriosis and thus define the course of the disease and assess objectively the impact of treatment.

\section{Patients and methods}

All the patients were infertile and had been comprehensively investigate with no diagnosis being reached before laparoscopy. Their median age wăs 28 years (range 21-35) and median duration of infertility 36 months (range 18-72). Each patient was made fully aware of the purpose of the study and of the possibility of allocation to a placebo before giving written consent. $T \mathrm{~T}$ protocol was approved by the local ethical committee.

Study design-The study was a randomised, double blind placebo controlled trial of gestrinone in the treatment of asymptomatic endo metriosis. Forty patients were recruited after a laparoscopy at which mild of moderate asymptomatic endometriosis had been diagnosed. The disease wh staged using the American Fertility Society scoring system. ${ }^{10}$ In this system score of 1 to 5 signifies mild endometriosis, 6 to 15 moderate endometriosi and greater than 15 severe disease. Only those patients with asymptomatic 